\title{
Current trends in the treatment of polycystic ovary syndrome with desire for children
}

This article was published in the following Dove Press journal:

Therapeutics and Clinical Risk Management

6 May 2009

Number of times this article has been viewed

\author{
Margalida E Sastre' \\ Maria O Prat' \\ Miguel Angel Checa ${ }^{1,2}$ \\ Ramon C Carreras' \\ 'Department of Obstetrics \\ and Gynaecology; ${ }^{2}$ Unit of \\ Endocrinological Gynaecology \\ and Human Reproduction, Hospital \\ del Mar, Autonomous University \\ of Barcelona, Barcelona, Spain
}

Correspondence: Miguel Angel Checa Servicio de Obstetricía y Ginecología, Hospital del Mar, Paseo Marítimo 25-25, Barcelona 08003, Spain

Tel +34932483129

Fax +34 932483254

Email macheca@hospitaldelmar.cat
Abstract: Polycystic ovary syndrome (PCOS), one of the most frequent endocrine diseases, affects approximately $5 \%-10 \%$ of women of childbearing age and constitutes the most common cause of female sterility regardless of the need or not for treatment, a change in lifestyle is essential for the treatment to work and ovulation to be restored. Obesity is the principal reason for modifying lifestyle since its reduction improves ovulation and the capacity for pregnancy and lowers the risk of miscarriage and later complications that may occur during pregnancy (gestational diabetes, pre-eclampsia, etc). When lifestyle modification is not sufficient, the first step in ovulation induction is clomiphene citrate. The second-step recommendation is either exogenous gonadotrophins or laparoscopic ovarian surgery. Recommended third-line treatment is in vitro fertilization. Metformin use in PCOS should be restricted to women with glucose intolerance.

Keywords: polycystic ovarian syndrome, clomiphene citrate, letrozole, lifestyle, pregnancy, obesity

Polycystic ovary syndrome (PCOS), one of the most frequent endocrine diseases, affects approximately 5\%-10\% of women of childbearing age ${ }^{1,2}$ and constitutes the most common cause of female sterility. This syndrome not only produces an alteration at reproduction level, but could also be labeled as a systemic involvement syndrome. Factors implicated in the low fertility in these patients include anovulation, ${ }^{1}$ increased risk of early miscarriage ${ }^{3}$ and late obstetric complications. ${ }^{4}$ Obesity is also a common finding in these patients ${ }^{5}$ and this condition appears to affect reproductive capacity. ${ }^{6,7}$

Polycystic ovary syndrome is an ovarian dysfunction. The main characteristics of the syndrome are hyperandrogenism and polycystic ovary morphology. Clinical manifestations include menstrual disorders, signs of hyperandrogenism and obesity. PCOS is associated with an increased risk of type 2 diabetes mellitus owing to the appearance of insulin resistance.

The diagnostic criteria of the syndrome were revised by the Rotterdam ESHRE/ ASRM-Sponsored PCOS Consensus Workshop Group in 2003 where the following criteria were established: oligoamenorrhea, clinical and biochemical signs of hyperandrogenism, and echographically confirmed polycystic ovary. Two of the three criteria are required for diagnosis. The advantages and disadvantages of these criteria, and particularly the different phenotypes and wide spectrum of the syndrome, have been discussed in later publications. ${ }^{8}$ submit your manuscript | www.dovepress.com

Dovepress 
Although progress has been made over the years in the unanimous acceptance of the diagnostic criteria worldwide, unification of criteria regarding treatment when children are desired remain to be established. Various publications ${ }^{9,10}$ have proposed a global update on lifestyle, medical ovulation-induced treatments, insulin-sensitizing agents, surgical treatments, or the application of assisted reproduction techniques. ${ }^{11}$ All of these were recently revisited by the Thessaloniki ESHRE/ASRM-Sponsored PCOS Consensus Workshop Group's report on consensus in infertility treatment related to PCOS.

\section{Changes in lifestyle}

Changes in the lifestyle of these patients must be the first recommendation, particularly when their body mass index (BMI) exceeds 28. It is well established that obesity is associated with ovulation, ${ }^{12}$ miscarriage, ${ }^{13}$ or late pregnancy complications (such as pre-eclampsia and gestational diabetes) ${ }^{14}$ Obesity is common in PCOS and is related to lack of or delayed response to different treatments such as clomiphene citrate (CC), ${ }^{15}$ gonadotrophins ${ }^{12,16}$ and surgical treatment of diathermy via laparoscopy. ${ }^{17}$

Weight loss appears to reverse the hormone disorders associated with PCOS (raised plasma sex hormone-binding globulin (SHBG) concentrations and lowered insulin and androgen levels) and thus improve ovulation ${ }^{11}$ and pregnancy rates. ${ }^{18}$ A $5 \%-10 \%$ loss of initial weight could suffice to re-establish ovarian function. The treatment of obesity includes modifications in lifestyle (diet and exercise) and medical and surgical treatment.

All these treatments must be performed during the pre-conception period and not jointly with reproduction therapies.

\section{Diet}

It is well known that a restricted calorie intake is necessary to lose weight. In patients without PCOS, low carbohydrate diets suffice to reduce weight, which appears to be particularly important in patients with PCOS and associated insulin resistance. ${ }^{19}$ Diets recommended for obese PCOS patients are low in calories with a reduced carbohydrate intake and any form of these diet can produce the 5\%-10\% loss necessary to re-establish ovarian function in these patients. Only two controlled, randomized studies compared the effect of different diets in patients with PCOS. ${ }^{18,19}$ Those studies showed that different diet patterns failed to produce significant changes in weight loss or reproduction results. ${ }^{18}$ In 2005, Reaven suggested that low-fat diets produce a decrease in hyperinsulinemia, which improves metabolic effects. ${ }^{19}$

\section{Exercise}

Several studies have attempted to establish the role of exercise $^{20}$ in the treatment of obese PCOS patients. None found significant differences when different diets, associated or not with exercise, were compared, although a longer weight loss maintenance time did appear to be associated in these patients. ${ }^{21}$ An increase in physical activity is recommended for PCOS patients, although they often present limitations. ${ }^{18}$

\section{Clomiphene citrate}

Clomiphene citrate is an estrogen antagonist that produces an increase in circulating follicle-stimulating hormone (FSH) concentrations by negative feedback blockage, thereby inducing follicular growth in patients with PCOS and ovulation. $\mathrm{CC}$ constitutes one of the first-line treatments for ovulation induction in these patients since it is economical, straightforward, has few adverse effects, and requires little monitoring. ${ }^{22}$

Treatment is started with a dose of $50 \mathrm{mg} /$ day for five days from the 2 nd to 5 th days of the cycle. The daily dose can be increased to $150 \mathrm{mg} /$ day without exceeding the US Food and Drug Administration (FDA) recommendations of $750 \mathrm{mg} /$ cycle $^{23}$ and six cycles can be performed.

Clomimphene citrate is indicated in patients with PCOS and anovulation, with normal FSH levels, but has certain limitations in patients with BMI $>30$ and advanced age. Legro and colleagues ${ }^{24}$ found significant differences in pregnancy rates in patients with BMI $>30$ compared with those with BMI $<30$.

Echographic cycle monitoring does not appear to ensure good results; therefore, in practice, some centers only monitor the first cycle to adjust the dose according to the patient's response. CC produces ovulation in $75 \%-80 \%$ of PCOS patients, ${ }^{22,25}$ although when the gestation rate is assessed, it nears $22 \%$ per ovulation cycle. These differences in results are attributed to the antiestrogenic effects of CC..$^{22,25}$ Multiple pregnancy rates are under $10 \%$ and hyperstimulation syndrome is rare. ${ }^{26}$

\section{Combined therapy: clomiphene citrate and metformin}

A randomized study ${ }^{27}$ found no increase in the pregnancy rate when $\mathrm{CC}$ and metformin alone or in combination were compared. Pregnancy and live birth rates were higher with 
CC compared with metformin, with similar adverse effects. Other studies ${ }^{28-31}$ observed benefits when metformin was included, however, they did not provide data on pregnancy rates and appeared to be small studies. There is currently no study that establishes metformin as an essential treatment for ovulation induction in women with PCOS.

A review published in $2005^{32}$ concluded that treatment with insulin-sensitizing agents must not be recommended in all patients with PCOS, but only in those who also have insulin resistance and obesity. However, if their use is necessary, metformin is the first choice insulin-sensitizing agent and that with which better results have been obtained than with placebo. Metformin is also an alternative for patients who present manifest hyperandrogenism. A recent American review $^{33}$ emphasized the use of metformin to improve associated disorders in PCOS patients (insulin resistance, type 2 diabetes, dyslipidemia, and cardiovascular alterations). Metformin is not as effective as CC for ovulation induction; however, their combined use is better than with placebo. The usefulness of metformin in reducing miscarriages and improving pregnancy outcome is also in doubt; for this reason, the dosage during pregnancy is not clear. The authors of the review concluded that metformin regains its usefulness in all these situations when PCOS patients present the aforementioned associated disorders.

\section{Insulin sensitizers}

Insulin resistance affects $10 \%-25 \%$ of the general population. This finding, together with hyperinsulinemia, appears to be present in a significant number of PCOS patients. Some authors believed it would be an independent component of obesity, ${ }^{34}$ while others associated insulin resistance in PCOS only with obese patients. ${ }^{35}$

In addition to the fertility disorders caused by insulin resistance and hyperinsulinism in women with PCOS, an increased risk of developing type 2 diabetes mellitus, ${ }^{36-38}$ dyslipidemias, and cardiovascular disease is also provoked. Acien and colleagues ${ }^{39}$ and Meirow and colleagues ${ }^{40}$ reported that approximately $10 \%$ of patients with PCOS and no obesity could present insulin resistance. Weight reduction in these patients is accompanied by an increase in insulin sensitivity ${ }^{41-44}$ followed by association of hyperandrogenism and restored ovulation, ${ }^{45-49}$ although the diet abandonment rate in these women owing to lack of motivation due to difficulty in achieving significant weight loss is high. This lack of adherence to diets and abandonment were the main reasons for using drugs to induce ovulation and achieve pregnancy.
Insulin-sensitizing agents, in particular metformin, are considered to be a first-line treatment in some regions where women with PCOS have a characteristic phenotype, since they normalize hyperandrogenism, induce ovulation, and protect from early pregnancy losses. ${ }^{50}$

Metformin, a hypoglycemia biguanide, is a category B drug (FDA recommendation). Its principal action is to lower glucose by inhibiting liver production without producing hypoglycemia in normoglycemic subjects, since it increases the number of receptors but not insulin secretion. Metformin improves glucose absorption, therefore the treatment improves insulin sensitivity and hyperandrogenism, increases SHBG concentration, lowers luteinizing hormone (LH) concentration and, in the liver, stimulates gluconeogenesis and inhibits glucogenolysis.

Metformin reduces total testosterone and raises SHBG levels, producing a decrease in the free testosterone index. It does not act on $\mathrm{BMI}^{51}$ but does appear to act on hirsutism and acne and induce the onset of regular cycles. ${ }^{52}$ Adverse effects of the drug include gastrointestinal disorders, mainly diarrhea, which improve when the dose is reduced or the drug is taken with meals. The most severe adverse effect is lactic acidosis.

Other insulin-sensitizing agents used are tiazolidindiones such as rosiglitazone and pioglitazone, which are effective in ovulation induction. They are category $\mathrm{C}$ (FDA). Their principal mechanism of action is to increase the capacity of muscle to metabolize glucose, which permits a reduction in insulin resistance.

One large study by Legro and colleagues reported a disadvantage of metformin compared with CC. The results did not appear to improve when metformin and $\mathrm{CC}$ were combined, except when BMI was $>35$. CC appeared to improve results compared with metformin when ovulation, conception, pregnancy, and live births were assessed.

Thus, from observing the different studies on the topic, and although some studies reported opposing results but did not seem to have significant scientific evidence, metformin would not appear to be a first-line treatment in patients with PCOS and the desire for children. Although metformin appears to be safe during pregnancy, ${ }^{24}$ interruption of the treatment is advised since no well-designed studies exist demonstrating its safety.

\section{Gonadotrophins and GnRH analogues}

The second possible line of therapy, after resistance to CC has been demonstrated in women with PCOS, is exogenous gonadotrophins. As revised by the Thessaloniki 
ESHRE/ASRM-Sponsored PCOS Consensus Workshop Group, the mechanism of action of gonadotrophins is to induce ovulation, maintain and provoke optimum follicle growth via the controlled administration of FSH, and achieve a follicle capable of being fertilized. The application of this concept is essential in women with PCOS since they have an excess of follicle production without reproductive capacity. ${ }^{53-55}$ The main drawbacks of gonadotrophins are that they provoke multiple follicle development, thereby increasing the risk of ovarian hyperstimulation syndrome (OHS) and multiple pregnancy. In order to minimize these drawbacks, anticonceptives have been used during the months prior to the start of the stimulation cycle and, above all in women with polycystic ovary, combined with metformin four to six weeks before the cycle starts to reduce follicle recruitment and avoid cycle cancellation. ${ }^{56-58}$

The usual FSH dose is $150 \mathrm{IU} /$ day, which is significantly reduced to $75-37.5 \mathrm{IU} /$ daily in women with polycystic ovary to lower the risk of hyperstimulation syndrome, which is raised in patients with PCOS. A maximum of six cycles with gonadotrophins is recommended since no response with six cycles signifies resistance. Two main protocols are used as shown in the consensus on infertility treatment related to polycystic ovary syndrome: the step-up and step-down regimens. ${ }^{53}$

The step-up regimen starts with a minimum dose, which increases according to the lack of follicle response. Control is made by ultrasound and the regimen is modified after one week of no follicle growth with a $50 \%$ increase each time as required. The duration of treatment is usually 7-14 days.

The step-down regimen starts with the maximum recommended dose, which is reduced as follicle response is achieved. The dose is reduced by $50 \%$ each time the regimen is changed.

Initially, treatment was started using the two protocols in the same way since with these regimens it is easier to avoid the main undesired effects of hyperstimulation syndrome and multiple pregnancies. However, recent studies have demonstrated greater safety for patients using the step-up regimen. ${ }^{59}$ The latest results with step-up regimens include approximately $70 \%$ ovulatory cycles, $20 \%$ pregnancies, and a $5.7 \%$ reduction in multiple pregnancies, and thus provide a therapeutic option to be considered. ${ }^{60}$

The search for improved efficacy has recently led to the consideration of the option of a combination of $\mathrm{GnRH}$ agonists and gonadotrophins. The use of LH may optimize follicle maturation and avoid anticipated spontaneous ovulation. As a drawback, it has been observed that high plasma LH levels are associated with a significant rise in lost pregnancies. At present, the regimen is not well established owing to the lack of studies confirming its usefulness and efficacy.

Monitoring is essential in gonadotrophins treatment to avoid the risk of hyperstimulation and multiple pregnancies. Cancellation criteria are not yet established. The latest studies state that for a cycle to be efficacious and produce a good result, there should not be more than two follicles $>14 \mathrm{~mm}$ or no more than three or four follicles of $10 \mathrm{~mm}$. In 2006, the ASRM advocated caution and strict control when the blood estradiol levels exceeded $2500 \mathrm{pg} / \mathrm{ml}$ during induction. ${ }^{61}$

\section{Letrozole}

Letrozole is a third-generation aromatase inhibitor (AI) used as an alternative to tamoxifen in women with breast cancer. It was introduced as an assisted reproduction treatment (ART) following the appearance of multiple adverse effects of CC, CC's scant therapeutic success, and the complexity of gonadotrophin treatment.

Letrozole inhibits estrogen production in the hypothalamuspituitary axis, which implies an increase in GnRH and FSH. It is believed that there exists a relative decrease in aromatase in PCOS women, which reduces the production of follicles responsible for efficacious ovulation. To use this relative deficit, aromatase inhibitors were considered in order to provoke ovulation, since their selective action of blocking the peripheral passage of androgens to estrogens reduces the quantity of estrogens, thereby producing a positive feedback in the pituitary, increasing $\mathrm{FSH}$, and optimizing ovulation. The advantage of letrozole is that it avoids peripheral antiestrogenic effects on the endometrium, while stimulating monofollicular growth. ${ }^{56,62,63}$

Aromatase inhibitors ${ }^{64}$ were proposed as a therapeutic option owing to their selectivity of action which is produced only at gonadal level without affecting other organs such as the brain, while avoiding the adverse effects produced by reduced estrogen in the system. Different generations of AI exist. For ART, the use of third-generation AI is recommended owing to their greater selectivity, greater potency, and lesser adverse effects. ${ }^{65,66}$ Of the third-generation AI, both letrozole and anastrozole are available. In vitro studies have shown letrozole to have greater potency and better plasma levels than anastrozole. For this reason, the majority of ART are performed with letrozole. ${ }^{65-67}$

Letrozole at $2.5-5 \mathrm{mg}$ is administered for five days and may be accompanied by FSH (at the normal doses of PCOS patients) and human chorionic gonadotropin (hCG; $10,000 \mathrm{IU})$ when the follicle diameter reaches $\geq 18 \mathrm{~mm}$ 
to program the ovulation. The half-life is now known to be approximately 45 hours and letrozole is completely eliminated at 17 days. ${ }^{68} \mathrm{~A}$ priori, the therapeutic option of AI would appear to be able to replace clomiphene citrate as a first-line treatment for patients with polycystic ovaries and those who fail to respond to conventional treatments.

This year saw the publication of a meta-analysis, which systematically reviewed all the articles on the use of letrozole in ART. ${ }^{69}$ This meta-analysis revealed a paucity of randomized studies and the difficulty in performing a correct statistical analysis owing to the lack of significant data. The authors showed with their comparison that results have not improved (ovulation cycle, ovulation induction, pregnancy) in a statistically significant manner with the use of letrozole.

Furthermore, recent studies showed the possibility of an increase in congenital heart diseases and skeletal malformations in neonates fertilized by ART using letrozole, although the teratogenicity is not confirmed. ${ }^{70}$ It can be seen from the above that scientific evidence is lacking for the use of letrozole as the ART of choice. ${ }^{53}$

\section{In vitro fertilization techniques}

The last possibility for achieving a full-term pregnancy in women with PCOS is to use in vitro reproduction techniques. ${ }^{53}$ Patients with polycystic ovaries are characterized by anovulatory cycles that conceptually are not an indication for in vitro fertilization (IVF) techniques. These techniques are used as a last resort when treatments with $\mathrm{CC}$, gonadotrophins, and letrozole have failed.

IVF is the first choice in cases of concomitant diseases both in women (severe endometriosis, neural tube defect, etc) and men (azoospermia, male factor) that reduce the effectiveness of other techniques. Several useful protocols, CC, gonadotrophins or AI, can be used in this type of patient, although the most standard protocol is long FSH-associated desensitization.

A meta-analysis published in 2006, which studied the results of conventional IVF techniques in women with PCOS, revealed more cycle cancellation ( $12.8 \%$ versus $4.1 \%$; odds ratio, $0.5 ; 95 \%$ confidence interval [CI]: $0.2-1.0)$ and that the duration of stimulation cycles was significantly longer in women with PCOS (1.2 days; 95\% CI: 0.9-1.5). ${ }^{71}$ There is evidence that the use of metformin improves viable pregnancy rates and reduces the incidence of ovarian hyperstimulation syndrome (OHS). ${ }^{72}$

OHS is the main complication to be feared in IVF techniques and even more so in patients with PCOS. There is currently no treatment to avoid it; thus, correct monitoring of the treatment will prevent the onset of this syndrome and its severity. The success of IVF techniques is similar to that of patients without PCOS, which implies that PCOS does not intervene in embryo implantation.

\section{Surgical techniques}

The surgical techniques traditionally employed were a bilateral wedge resection and laparoscopy surgery of the ovary using a diathermy loop or laser. The former, despite its aggressivity, is widely used in current practice, but is not currently used as a therapeutic alternative in PCOS patients. ${ }^{53}$ The latter consists of ovarian drilling (multiple controlled perforation of the ovary). ${ }^{73}$ It has recently been reported $^{53}$ that the sole indication for laparoscopy, at present, is in cases of resistance to $\mathrm{CC}$, ie, in patients who, despite the treatment, do not achieve ovulatory cycles. Laparoscopy has also been recommended in patients with LH hypersecretion, those with an anatomical-functional problem of the pelvis, or those who reside far from a center where the treatment can be closely controlled. It is not a treatment of choice since its therapeutic effect lapses at six months and may thus be used only as a last resort. ${ }^{53,56,74,75}$ The danger implicit in these techniques is the extent of the lesion and repercussions on ovarian parenchyma. For this reason, they are not recommended as a prevention of hyperstimulation (OHS) ${ }^{76}$

A further possibility for laparoscopy is to combine it with another ART such as bilateral salpingectomy for bilateral hydrosalpinx followed by an IVF technique, although this situation is not usual in patients with PCOS. In conclusion, laparoscopy as an ART would be an aggressive alternative and its indication would thus have to be contextualized and tailor-made to the patient.

\section{Conclusions}

Symptoms in women with PCOS range widely: from those with biochemical disorders that do not affect clinical status to those who fulfill all the criteria of the syndrome. For this reason treatment should be individualized according to whether or not there is a desire for children.

Regardless of the need or not for treatment, a change in lifestyle is essential for the treatment to work and ovulation to be restored. Obesity is the principal reason for modifying lifestyle since its reduction improves ovulation and the capacity for pregnancy and lowers the risk of miscarriage and later complications that may occur during pregnancy (gestational diabetes, pre-eclampsia, etc). 
It has also been demonstrated that the essential step to achieve significant weight loss is to reduce calorie intake, regardless of the physical exercise that may be associated.

The next step, if there is a desire for children, is to apply an ovulation-inducing treatment. In women with PCOS, the first option is currently CC. However, despite CC being the first choice, many possible alternatives are being established: gonadotrophins, AIs, etc. The problem is a lack of scientific evidence showing their efficacy and possible superiority. Thus, more randomized clinical trials are required to demonstrate significant differences among treatments. In summary, the treatment of PCOS-associated infertility consists of efficacious ovulation induction to achieve homeostasis.

The choice of treatment should be contextualized and individualized. Treatment is started not to induce ovulation with hormone therapy but to prepare the best context possible to protect a future pregnancy. Thus, an improved lifestyle and above all weight loss must be emphasized. In cases of insulin resistance that do not improve with slimming, drugs such as metformin that help to regulate homeostasis and facilitate ovulation recovery can be used.

\section{Disclosure}

The authors report no conflicts of interest in this work.

\section{References}

1. Hull MGR. Epidemiology of infertility and polycystic ovarian disease: endocrinological and demographic studies. Gynecol Endocrinol. 1987;1:235-245.

2. Polson DW, Adams J, Wadsworth J, Franks S. Polycystic ovaries - a common finding in normal women. Lancet. 1988;1:870-872.

3. Homburg R, Armar NA, Eshel A, Adams J, Jacobs HS. Influence of serum luteinizing hormone concentrations on ovulation, conception, and early pregnancy loss in polycystic ovary syndrome. BMJ. 1988;297: 1024-1026.

4. Boomsma CM, Eijkemans MJ, Hughes EG, Visser GH, Fauser BC, Macklon NS. A meta-analysis of pregnancy outcomes in women with polycystic ovary syndrome. Hum Reprod Update. 2006;12:673-683.

5. Ehrmann DA. Polycystic ovary syndrome. N Engl J Med. 2005;352: 1223-1236.

6. Bolumar F, Olsen J, Rebagliato M,Saez-Lloret I, Bisanti L. Body mass index and delayed conception: a European multicenter study on infertility and subfecundity. Am J Epidemiol. 2000;151:1072-1079.

7. Weiss JL, Malone FD, Emig D, et al. Obesity, obstetric complications and cesarean delivery rate - a population-based screening study. Am J Obstetric Gynecol. 2004;190:1091-1097.

8. Rotterdam ESHRE/ASRM-Sponsored PCOS Consensus Workshop Group. Revised 2003 consensus on diagnostic criteria and longterm health risks related to polycystic ovary syndrome. Fertil Steril. 2004;81(1):19-25.

9. Azziz R, Carmina E, Dewailly D, et al. Positions statement: criteria for defining polycystic ovary syndrome as a predominantly hyperandrogenic syndrome: an Androgen Excess Society guideline. J Clin Endocrinol Metab. 2006;91:4237-4245.

10. Franks S. Controversy in clinical endocrinology: diagnosis of polycystic ovarian syndrome: in defense of the Rotterdam criteria. J Clin Endocrinol Metab. 2006;91:786-789.
11. Pasquali R, Pelusi C, Genghini S, Cacciari M, Gambineri A. Obesity and reproductive disorders in women. Hum Reprod Update. 2003;9: 359-372.

12. Mulders AG, Laven JS, Eijkemans MJ, Hughes EG, Fauser BC. Patient predictors for outcome of gonadotrophin ovulation induction in women with normogonadotrophic anovulatory infertility: a meta-analysis. Hum Reprod Update. 2003;9:429-449.

13. Froen JF, Arnestad M, Frey K, Vege A, Saugstad OD, Stray-Pedersen B. Risk factors for sudden intrauterine unexplained death: epidemiologic characteristics of singleton cases in Oslo, Norway, 1986-1995. Am J Obstet Gynecol. 2001;184:694-702.

14. Boomsma CM, Eijkemans MJ, Hughes EG, Visser GH, Fauser BC, Macklon NS. A meta-analysis of pregnancy outcomes in women with polycystic ovary syndrome. Hum Reprod Update. 2006;12: 673-683.

15. Imani B, Eijkemans MJ, te Velde ER, Habbema JD, Fauser BC. Predictors of chances to conceive in ovulatory patients during clomiphene citrate induction of ovulation in normogonadotropic oligoamenorrheic infertility. J Clin Endocrinol Metab. 1999;84: 1617-1622.

16. Balen A. Surgical management of PCOS. Best Pract Res Clin Endocrinol Metab. 2006;20:271-280.

17. Gjönnaess H. Ovarian electrocautery in the treatment of women with polycystic ovary syndrome (PCOS). Factors affecting the results. Acta Obstet Gynecol Scand. 1994;73:407-412.

18. Moran LJ, Brinkworth G, Noakes M, Norman RJ. Effects of lifestyle modification in polycystic ovarian syndrome. Reprod Biomed Online. 2006;12:569-578.

19. Reaven GM. The insulin resistance syndrome: definition and dietary approaches to treatment. Annu Rev Nutr. 2005;25:391-406.

20. Bruner B, Chad K, Chizen D. Effects of exercise and nutritional counseling in women with polycystic ovary syndrome. Appl Physiol Nutr Metab. 2006;31:384-391.

21. Knowler WC, Barrett-Connor E, Fowler SE, et al. Reduction in the incidence of type 2 diabetes with lifestyle intervention or metformin. N Engl J Med. 2002;346:393-403.

22. Homburg R. Clomiphene citrate - end of an era? A minireview. Hum Reprod. 2005;20:2043-2051.

23. Dickey RP, Taylor SN, Curole DN, Rye PH, Pyrzak R. Incidence of spontaneous abortion in clomiphene pregnancies. Hum Reprod. 1996;11:2623-2628.

24. Legro RS, Barnhart HX, Schlaff WD, et al. Clomiphene, metformin, or both for infertility in the polycystic ovary syndrome. $N$ Engl J Med. 2007;356:551-566.

25. Messinis IE. Ovulation induction: a mini review. Hum Reprod. 2005;20:2688-2697.

26. Eijkemans MJ, Imani B, Mulders AG, Habbema JD, Fauser BC. High singletons live birth rate following classical ovulation induction in normogonadotrophic anovulatory infertility (WHO 2). Hum Reprod. 2003; 18:2357-2362.

27. Legro RS, Myers E. Surrogate end-points or primary outcomes in clinical trials in women with polycystic ovary syndrome? Hum Reprod. 2004;19(8):1697-1704.

28. Palomba S, Orio F Jr, Falbo A, et al. Prospective parallel randomized, double blind, double-dummy controlled clinical trial comparing clomiphene citrate and metformin as the first-line treatment for ovulation induction in non-obese anovulatory women with polycystic ovary syndrome. J Clin Endocrinol Metab. 2005;90:4068-4074.

29. Vandermolen DT, Ratts VS, Evans WS, Stovall DW, Kauma SW, Nestler JE. Metformin increases the ovulatory rate and pregnancy rate from clomiphene citrate in patients with polycystic ovary syndrome who are resistant to clomiphene citrate alone. Fertil Steril. 2001;75: 310-315.

30. Kocak M, Caliskan E, Simsir C, Haberal A. Metformin therapy improves ovulatory rates, cervical scores, and pregnancy rates in clomiphene citrate-resistant women with polycystic ovary syndrome. Fertil Steril. 2002;77:101-106. 
31. Lord JM, Flight IH, Norman RJ. Metformin in polycystic ovary syndrome: systematic review and meta-analysis. BMJ. 2003;327: 951-953.

32. Checa MA, Requena A, Salvador C, et al; Reproductive Endocrinology Interest Group of the Spanish Society of Fertility. Insulin-sensitizing agents: use in pregnancy and as therapy in polycystic ovary syndrome. Hum Reprod Update. 2005;11(4):375-390.

33. Mathur R, Alexander CJ, Yano J, Trivax B, Azziz R. Use of metformin in polycystic ovary syndrome. Am J Obstet Gynecol. 2008;199(6): 596-609.

34. Armstrong VL, Wiggam MI, Ennis CN, et al. Insulin action and insulin secretion in polycystic ovary syndrome treated with ethinyl oestradiol/ cyproterone acetate. QJ Med. 2001;94:31-37.

35. Holte J, Bergh T, Berne Ch, Wide L, Lithell H. Restored insulin sensitivity but persistently increased early insulin secretion after weight loss in obese women with polycystic ovary syndrome. J Clin Endocrinol Metab. 1995;80:2586-2593.

36. Azziz R, Ehrmann DA, Legro RS, Fereshetian AG, O'Keefe M, Ghazzi MN; PCOS/Troglitazone Study Group. Troglitazone decreases adrenal androgen levels in women with polycystic ovary syndrome. Fertil Steril. 2003;79:927-937.

37. Legro RS, Kunselman AR, Dodson WC, Dunaif A. Prevalence and predictors of risk for type 2 diabetes mellitus and impaired glucose tolerance in polycystic ovary syndrome: a prospective, controlled study in 254 affected women. J Clin Endocrinol Metab. 1999;84:165-169.

38. Ovalle F, Azziz R. Insulin resistance, polycystic ovary syndrome, and type 2 diabetes mellitus. Fertil Steril. 2002;77:1095-1105.

39. Meirow D, Yossepowitch O, Rosler A, Brzezinski A, Schenker JG, Laufer Nand Raz I. Insulin resistant and non-resistant polycystic ovary syndrome represent two clinical and endocrinological subgroups. Hum Reprod. 1995;10:1951-1956.

40. Acien P, Querada F, Matallın P, et al. Insulin, androgens, and obesity in women with and without polycystic ovary syndrome: a heterogeneous group of disorders. Fertil Steril. 1999;72:32-40.

41. Van Dam EW, Roelfsema F, Veldhuis JD, et al. Increase in daily LH secretion in response to short-term calorie restriction in obese women with PCOS. Am J Physiol Endocrinol Metab. 2002;282: E865-E872.

42. Wahrenberg H, Ek I, Reynisdottir S, Carlstrom K, Bergqvist A, Arner P. Divergent effects of weight reduction and oral anticonception treatment on adrenergic lipolysis regulation in obese women with the polycystic ovary syndrome. J Clin Endocrinol Metab. 1999;84: 2182-2187.

43. Moran LJ, Noakes M, Clifton PM, Tomlinson L, Galletly C, Norman RJ. Dietary composition in restoring reproductive and metabolic physiology in overweight women with polycystic ovary syndrome. J Clin Endocrinol Metab. 2003;88:812-819.

44. Holte J, Bergh T, Berne C, Wide L, Lithell H. Restored insulin sensitivity but persistently increased early insulin secretion after weight loss in obese women with polycystic ovary syndrome. J Clin Endocrinol Metab. 1995;80:2586-2593.

45. Kiddy DS, Hamilton-Fairley D, Seppala M, et al. Diet-induced changes in sex hormone binding globulin and free testosterone in women with normal or polycystic ovaries:correlation with serum insulin and insulinlike growth factor-I. Clin Endocrinol (Oxf). 1989;31:757-763.

46. Pasquali R, Antenucci D, Casimirri F, et al. Clinical and hormonal characteristics of obese amenorrheic hyperandrogenic women before and after weight loss. J Clin Endocrinol Metab. 1989;68:173-179.

47. Hamilton-Fairley D, Kiddy D, Anyaoku V, Koistinen R, Seppala M, Franks S. Response of sex hormone binding globulin and insulin-like growth factor binding protein-1 to an oral glucose tolerance test in obese women with polycystic ovary syndrome before and after calorie restriction. Clin Endocrinol (Oxf). 1993;39:363-367.

48. Jakubowicz DJ, Nestler JE. 17 alpha-Hydroxyprogesterone responses to leuprolide and serum androgens in obese women with and without polycystic ovary syndrome offer dietary weight loss. J Clin Endocrinol Metab. 1997;82:556-560.
49. Crosignani PG, Colombo M, Vegetti W, Somigliana E, Gessati A, Ragni G. Overweight and obese anovulatory patients with polycystic ovaries: parallel improvements in anthropometric indices, ovarian physiology and fertility rate induced by diet. Hum Reprod. 2003;18:1928-1932.

50. Seli E, Duleba AJ. Should patients with polycystic ovarian syndrome be treated with metformin? Hum Reprod. 2002;17:2230-2236.

51. Lord JM, Flight IHK, Norman RJ. Metformin in polycystic ovary syndrome: systematic review and meta-analysis. BMJ. 2003;327: 951-956.

52. Genazzani AD, Battaglia C, Malavasi B, Strucchi C, Tortonali F, Gamba O. Metformin administration modulates and restores luteinizing hormone spontaneous episodic secretion and ovarian function in nonobese patients with polycystic ovary syndrome. Fertil Steril. 2004;81:114-119.

53. Thessaloniki ESHRE/ASRM-Sponsored PCOS Consensus Workshop Group. Consensus on infertility treatment related to polycystic ovary syndrome. Fertil Steril. 2008;89:505-522.

54. Brown JB. Pituitary control of ovarian function - concepts derived from gonadotrophin therapy. Aus NZ J Obstet Gynaecol. 1978;18:46-54.

55. Braid DT. A model for follicular selection and ovulation: lessons from superovulation. J Steroid Biochem. 1987;27:15-23.

56. Remohí J, Bellver J, Domingo J, Bosch E, Pellicer A. Manual práctico de esterilidad y reproducción humana: aspectos prácticos. Capítulo 5; diagnóstico y tratamiento del síndrome de ovarios poliquísticos. 3rd ed. Madrid, Spain: McGraw-Hill/Interamericana; 2008. p. 49-60.

57. Mitwally M, Casper RF. Use of an aromatase inhibitor for induction of ovulation in patients with an inadequate response to clomiphene citrate. Fertil Steril. 2001;75:305-309.

58. Mitwally M, Casper RF. Aromatase inhibition improves ovarian response to follicle-stimulating hormone in poor responders. Fertil Steril. 2002;77:776-780.

59. Filicori M, Cognigni GW, Taraborrelli S, et al. Luteinizing hormone activity in menotropins optimizes folliculogenesis and treatment in controlled ovarian stimulation. J Clin Endocrinol Metab. 2001;86:337-343.

60. Christin-Maitre S, Hugues JN. A comparative randomized multicentric study comparing the step-up versus step-down protocol in polycystic ovary syndrome. Human Reprod. 2003;18:1626-1631.

61. Homburg R, Howlewa CM. Low-dose FSH therapy for anovulatory infertility associated with polycystic ovary syndrome: rationale, results, reflections and refinements. Hum Reprod Update. 1999;5: 493-499.

62. Dolson WC, MoessnerJ, Millar J, et al. A randomized comparison of the methods of the sperm preparation for intrauterine insemination. Fertil Steril. 1998;70:574-575.

63. Carroll N, Palmer JR. A comparison of intrauterine and intracervical insemination with frozen donor sperm: a meta-analysis. Fertil Steril. 2001;75:656-660.

64. Practice Committee of the American Society for Reproductive Medicine. Ovarian hyperstimulation syndrome. Fertil Steril. 2006; 86(5 Suppl):S178-S183.

65. Millar RM, Dixon JM. Antiaromatase agents: preclinical data and neoadjuvant therapy. Clin Breast Cancer. 2000;1(Suppl 1):S94-S95.

66. Holzer H, Casper R, Tulandi T. A new era in ovulation induction. Fertil Steril. 2006;85:1774-1777.

67. Bhatnagar AS, Häusler A, Schieweck K, Lang M, Bowman R. Highly selective inhibition of estrogen biosynthesis by CGS 20267, a new non-steroidal aromatase inhibitor. J Steroid Biochem Mol Biol. 1990;37:1021-1027.

68. Noriega-Portella L, Noriega-Hoces L, Delgado A, Rubio J, GonzalesCastañeda C, Gonzales GF. Effect of letrozole at $2.5 \mathrm{mg}$ or $5.0 \mathrm{mg} / \mathrm{day}$ on ovarian stimulation with gonadotropins in women undergoing intrauterine insemination. Fertil Steril. 2008;90:1818-1825.

69. Requena A, Herrero J, Landeras J, et al; Reproductive Endocrinology Interest Group of the Spanish Society of Fertility. Use of letrozole in assisted reproduction: a systematic review and meta-analysis. Hum Reprod Update. 2008;14:571-582. 
70. Tulandi T, Martin J, Al-Fadhli R, et al. Congenital malformations among 911 newborns conceived after infertility treatment with letrozole or clomiphene citrate. Fertil Steril. 2006;85:1761-1765.

71. Heijnem EM, Eijkemans MJ, Hughes EG, Laven JS, Macklon NS, Fauser BC. A meta-analysis of outcomes of conventional IVF in women with polycystic ovary syndrome. Hum Reprod Update. 2006;12: 13-21.

72. Tang T, Glanville J, Orsi N, Barth JH, Balen AH. The use of metformin for women with PCOS undergoing IVF treatment. Human Reprod. 2006;21:1416-1425.

73. Gjönnaess H. Polycystic ovarian syndrome treated by ovarian electrocautery through the laparoscope. Fertil Steril. 1984;41:20-25.
74. Moreno C, Zuzuarregui J, Muñoz E, et al. Insemination artificial. In: Remohí J, Romero JL, Pellicer A, et al (editors). Manual práctico de esterilidad y reproducción humana. Madrid, Spain: McGraw-Hill/ Interamericana; 2000. p. 81-95.

75. Tummon IS, Hening I, Radwanska E, et al. Persistent ovarian cysts following administration of human menopausal and chorionic gonadatrophins: an attenuated form of ovarian hyperstimulation syndrome. Fertil Steril. 1998;49:244-248.

76. Rimington MR, Walter SM, Shaw RW. The use of laparoscopy ovarian electrocautery in preventing cancellation of in-vitro fertilization treatment cycles due to risk of ovarian hyperstimulation syndrome in women with polycystic ovaries. Hum reprod. 1997;12:1443-1447.

\section{Publish your work in this journal}

Therapeutics and Clinical Risk Management is an international, peerreviewed journal of clinical therapeutics and risk management, focusing on concise rapid reporting of clinical studies in all therapeutic areas outcomes, safety, and programs for the effective, safe, and sustained use of medicines. This journal is indexed on PubMed Central, CAS,
EMBase, Scopus and the Elsevier Bibliographic databases. The manuscript management system is completely online and includes a very quick and fair peer-review system, which is all easy to use. Visit http://www.dovepress.com/testimonials.php to read real quotes from published authors.

Submit your manuscript here: http://www.dovepress.com/therapeutics-and-clinical-risk-management-journal 